\title{
Association between poor therapy adherence to inhaled corticosteroids and tiotropium and morbidity and mortality in patients with COPD
}

This article was published in the following Dove Press journal: International Journal of COPD

\author{
Kirsten Koehorst-ter \\ Huurne \\ Catharina GM Groothuis- \\ Oudshoorn ${ }^{2}$ \\ Paul DLPM vanderValk' \\ Kris LL Movig ${ }^{3}$ \\ Job van der Palen ${ }^{4,5}$ \\ Marjolein Brusse-Keizer ${ }^{4}$ \\ 'Department of Pulmonary Medicine, \\ Medisch Spectrum Twente, Enschede, \\ the Netherlands; ${ }^{2}$ Department of \\ Health Technology and Services \\ Research, University of Twente, \\ Enschede, the Netherlands; \\ ${ }^{3}$ Department of Clinical Pharmacy, \\ Medisch Spectrum Twente, Enschede, \\ the Netherlands; ${ }^{4}$ Medical School \\ Twente, Medisch Spectrum Twente, \\ Enschede, the Netherlands; \\ ${ }^{5}$ Department of Research \\ Methodology, Measurement, and \\ Data Analysis, University of Twente, \\ Enschede, the Netherlands
}

Aim: The aim of this study was to analyze the association between therapy adherence to inhaled corticosteroids (ICSs) and tiotropium on the one hand and morbidity and mortality in COPD on the other hand.

Methods: Therapy adherence to ICSs and tiotropium over a 3-year period of, respectively, 635 and 505 patients was collected from pharmacy records. It was expressed as percentage and deemed optimal at $\geq 75-\leq 125 \%$, suboptimal at $\geq 50 \%-<75 \%$, and poor at $<50 \%$ (underuse) or $>125 \%$ (overuse). The association between adherence and time to first hospital admission for an acute exacerbation of chronic obstructive pulmonary disease (AECOPD), community acquired pneumonia (CAP), and mortality was analyzed, with optimal use as the reference category.

Results: Suboptimal use and underuse of ICSs and tiotropium were associated with a substantial increase in mortality risk: hazard ratio (HR) of ICSs was 2.9 (95\% CI 1.7-5.1) and 5.3 (95\% CI 3.3-8.5) and HR of tiotropium was 3.9 (95\% CI 2.1-7.5) and 6.4 (95\% CI 3.8-10.8) for suboptimal use and underuse, respectively. Suboptimal use and overuse of tiotropium were also associated with an increased risk of CAP, HR 2.2 (95\% CI 1.2-4.0) and HR 2.3 (95\% CI 1.2-4.7), respectively. Nonadherence to tiotropium was also associated with an increased risk of severe AECOPD: suboptimal use HR 3.0 (95\% CI 2.01-4.5), underuse HR 1.9 (95\% CI 1.2-3.1), and overuse HR 1.84 (95\% CI 1.1-3.1). Nonadherence to ICSs was not related to time to first AECOPD or first CAP.

Conclusion: Poor adherence to ICSs and tiotropium was associated with a higher mortality risk. Furthermore, nonadherence to tiotropium was associated with a higher morbidity. The question remains whether improving adherence can reduce morbidity and mortality.

Keywords: COPD, adherence, morbidity, mortality, pneumonia, exacerbation, hospitalization

\section{Introduction}

COPD management aims at reducing symptoms, exacerbations, and mortality by giving appropriate pharmacotherapy. ${ }^{1-3}$ Treatment strategies contain long-acting muscarinic agonists (LAMAs) like tiotropium, inhaled corticosteroids (ICSs), long-acting beta agonists (LABAs), and combination drugs.

Several studies have described the risk of pneumonia associated with the use of ICSs. The TOwards a Revolution in COPD Health (TORCH) study was the first to show an increased risk of pneumonia for ICS users, and recently, the Understanding Potential Long-Term Impacts on Function with Tiotropium (UPLIFT) study also showed higher incidence rates of pneumonia for ICS users. ${ }^{4-6}$ The magnitude of this risk, the effects of different preparations and doses, and the mechanism of this effect
Correspondence: Kirsten Koehorst-ter Huurne

Department of Pulmonary Medicine, Medisch Spectrum Twente,

PO Box 50000, 7500 KA Enschede, the Netherlands

Tel +3I 534872643

Fax +3I 534872676

Email kirstenterhuurne@gmail.com 
remain unclear. ${ }^{7,8}$ Although the risk-benefit ratio for ICSs is under debate, the Global Initiative for Chronic Obstructive Lung Disease (GOLD) guidelines still suggest considering the use of ICSs in patients with severe airflow limitation or in those who are at a high risk of exacerbations. ${ }^{9,10}$

The effectiveness of inhaled medications is strongly influenced by the patient's medication adherence, with a better adherence showing reduced risk of death and hospitalization due to COPD exacerbations for fluticasone/salmeterol and tiotropium. ${ }^{2,3,11}$ In most of these studies, adherence was defined as poor $(<75 \%$ or $<80 \%)$ or good. In the Cohort of Mortality and Inflammation in COPD (COMIC) cohort, we have, however, shown that there are also many patients who overuse $(>125 \%)$ or strongly underuse $(<50 \%)$ ICSs and despite the high percentage of optimal use with tiotropium, underuse and overuse are observed for this medication as well. ${ }^{12}$ It is expected that these patients will have a different risk for a COPD exacerbation that needs hospitalization (acute exacerbation of chronic obstructive pulmonary disease [AECOPD]), community acquired pneumonia (CAP), and mortality compared to patients with optimal ( $\geq 75-\leq 125 \%$ ) or suboptimal $(\geq 50-<75 \%)$ adherence. Therefore, in this manuscript, the association between therapy adherence (underuse, suboptimal use, optimal use, and overuse) with ICSs and tiotropium and time to first hospital admission for a severe AECOPD, CAP, and mortality is described.

\section{Methods}

\section{Settings and study population}

This study is part of the COMIC study, a single-center prospective cohort study in Enschede, the Netherlands. Of the 1,503 patients who were screened for eligibility from December 2005 to April 2010, 795 COPD patients were included. All surviving patients completed the 3-year follow-up period. All patients provided written informed consent, including consent for collecting pharmacy records during the studied period. The study was approved by the Medical Ethics Committee Twente (P05-49) and was conducted according to the principles of the Declaration of Helsinki.

For inclusion and exclusion criteria, see previous publications. $^{12-14}$

\section{Baseline measurements}

Demographic data were collected from medical records at baseline. Data on common comorbidities such as myocardial infarction, congestive heart failure, and diabetes mellitus were obtained from medical records. Lung function was measured by spirometry, performed according to standardized guidelines. ${ }^{15}$ The modified Medical Research Council (mMRC) dyspnea grade was obtained at the stable state. ${ }^{16}$

\section{Therapy adherence}

Therapy adherence was recorded from patients' pharmacy records. If patients used more than one medication delivery system or switched between various brands of ICSs (including combination preparations) during follow-up, adherence data were combined for the calculation of the therapy adherence of ICSs. For adherence to tiotropium, prescriptions of HandiHaler and Respimat were used.

Theoretical duration of exposure was calculated using information on dispensing date, total supply, and dosage regimen. We computed the total number of days for which patients had collected medication during follow-up and divided this by the total number of days between the first and last medication collection during follow-up plus the day's supply of the last refill. We excluded patients for whom medication was prescribed only once or was used $<90$ days. We set the limit for optimal adherence at $\geq 75 \%$. Next to this, we decided to choose two lower cutoff points to distinguish between suboptimal use and underuse and an upper cutoff point as well for optimal adherence $(>125 \%)$, in order to be able to identify overuse. ${ }^{2,17-19}$ Adherence was deemed good if it was $\geq 75-\leq 125 \%$, suboptimal if it was between $\geq 50-<75 \%$, and poor if it was $<50 \%$ (underuse) or $>125 \%$ (overuse). ${ }^{12}$

Since adherence can change over time, adherence was computed for 6-month intervals. For each 6-month period, the total number of days for which patients had collected medication was divided by the total number of days between the first and last medication collection during these 6 months and multiplied by $100 .^{20}$ If a refill period went over a 6-month boundary, the prescription was taken into account in both intervals.

\section{Morbidity and mortality}

Morbidity was defined as the time to first hospitalization for a severe AECOPD and time to first CAP. An AECOPD was defined as an acute negative change from baseline, reported by the patient, in dyspnea, sputum volume, color of sputum (yellowish or greenish sputum), and/or cough, which may warrant additional treatment of prednisolon with or without antibiotics by a physician in a patient with underlying COPD. CAP was defined as an acute respiratory tract illness associated with radiographic shadowing on a chest radiograph consistent with an infection, which was neither preexisting 
Table I Baseline characteristics of patients using ICSs (including combined preparations)

\begin{tabular}{|c|c|c|c|c|c|c|}
\hline \multirow[t]{2}{*}{ Characteristics } & \multirow{2}{*}{$\begin{array}{l}\text { Overall } \\
\text { ICSs } \\
(n=635)\end{array}$} & \multicolumn{4}{|c|}{ Adherence category: first 6 months of ICS use } & \multirow[t]{2}{*}{$p$-value } \\
\hline & & $\begin{array}{l}\text { Optimal use, } \\
\geq 75-\leq 125 \% \\
(n=365)\end{array}$ & $\begin{array}{l}\text { Suboptimal } \\
\text { use, } \geq \mathbf{5 0}-<75 \% \\
(n=92)\end{array}$ & $\begin{array}{l}\text { Underuse, } \\
<\mathbf{5 0 \%} \\
(\mathbf{n}=\mathbf{7 5})\end{array}$ & $\begin{array}{l}\text { Overuse, } \\
>125 \% \\
(n=103)\end{array}$ & \\
\hline Age (years), mean (SD) & $67.1(9.7)$ & $66.2(9.5)$ & $69.1(10.3)$ & $67.1(9.8)$ & $68.5(9.6)$ & 0.035 \\
\hline Sex (male), n (\%) & $377(59.4)$ & $221(60.5)$ & $61(66.3)$ & $39(52.0)$ & $56(54.4)$ & 0.187 \\
\hline \multicolumn{7}{|l|}{ Smoking status, $n(\%)$} \\
\hline Current smoker & $176(27.7)$ & $86(23.6)$ & $25(27.2)$ & $21(28.0)$ & $44(42.7)$ & 0.002 \\
\hline Ex-smoker & $459(72.3)$ & $279(76.4)$ & $67(72.8)$ & $54(72.0)$ & $59(57.3)$ & \\
\hline \multicolumn{7}{|l|}{ Lung function, mean (SD) } \\
\hline $\mathrm{FEV}_{1}(\mathrm{~L})$ & $1.4(0.56)^{\mathrm{a}}$ & $1.4(0.55)$ & $1.3(0.66)$ & $1.3(0.59)$ & $1.3(0.46)$ & 0.035 \\
\hline $\mathrm{FEV}, \%$ predicted & $51.2(18.4)^{\mathrm{a}}$ & $52.3(17.7)$ & $49.4(20.5)$ & $50.1(21.1)$ & $49.7(16.8)$ & 0.379 \\
\hline $\mathrm{FEV}_{1} / \mathrm{VC}$ ratio & $43.5(13.3)^{\mathrm{a}}$ & $43.5(12.3)$ & $42.7(14.2)$ & $45.6(16.1)$ & $42.8(13.8)$ & 0.483 \\
\hline mMRC, mean $(S D)^{b}$ & $1.8(1.26)$ & $1.6(1.2)$ & $2.0(1.3)$ & $2.2(1.3)$ & $2.0(1.3)$ & 0.000 \\
\hline Tiotropium use, n (\%) & $440(69.3)$ & $265(72.6)$ & $70(76.1)$ & $40(53.3)$ & $65(63.1)$ & 0.002 \\
\hline \multicolumn{7}{|l|}{ Comorbidities, n (\%) } \\
\hline Heart failure & $100(15.8)$ & $52(14.2)$ & $19(20.7)$ & II (I4.7) & $18(17.5)$ & 0.460 \\
\hline Myocardial infarction & $26(4.1)$ & $8(2.2)$ & $8(8.7)$ & $4(5.3)$ & $6(5.8)$ & 0.016 \\
\hline Diabetes mellitus & $36(5.7)$ & $16(4.4)$ & $5(5.4)$ & $5(6.7)$ & $10(9.7)$ & 0.220 \\
\hline
\end{tabular}

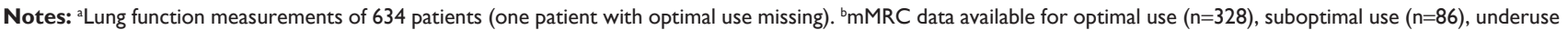
$(n=68)$, and overuse $(n=97)$.

Abbreviations: ICS, inhaled corticosteroid; SD, standard deviation; FEV , forced expiratory volume in I second; FEV \% predicted, percentage of predicted forced expiratory volume in I second; VC, vital capacity; mMRC, modified Medical Research Council.

nor of any other known cause. ${ }^{21}$ All X-rays were double read by a radiologist and a pulmonary physician. In case of doubtful shadows in the report, the X-ray was presented to another pulmonary physician for final judgment. Survival was based on all-cause mortality. Date of death was verified from the municipal administration.

\section{Statistics}

Baseline characteristics are reported as mean with standard deviation (SD) or median with interquartile range (IQR) for continuous variables. Categorical variables are displayed as numbers with corresponding percentages. Differences in baseline characteristics between the adherence categories measured in the first 6-month period were analyzed by analysis of variance (ANOVA) or the Kruskal-Wallis test for continuous variables and the chi-square test for categorical variables.

To assess the relationship between therapy adherence to ICSs, time to first severe AECOPD, time to first CAP, and time to death, Cox regression was used with time-varying coefficients. ${ }^{22,23}$ The same analyses were conducted for tiotropium.

For each separate multiple-variable Cox regression model, all baseline characteristics (Tables 1 and 2) that were associated with both the studied adherence of the model and time to severe AECOPD, CAP, or mortality at $p<0.10$ were entered as potential confounders. All statistical calculations were carried out using the SPSS statistical package (version 21.0) and $R$ package (version 3.4.1). ${ }^{24}$

\section{Results \\ Baseline characteristics}

Table 1 lists the baseline characteristics of patients using ICSs and Table 2 of those using tiotropium. A total of 635 patients used ICSs with an overall median duration use of 32.5 months (IQR 20.5-36.6 months), varying per ICS preparation between 9.3 and 31.2 months (Table 3). In all, 505 patients used tiotropium with an overall median duration use of 30.0 months (IQR 15.0-35.0 months; Respimat 20.1 months [IQR 9.9-29.7 months] and HandiHaler 30.8 months [IQR 17.5-36.1 months]).

Of the baseline characteristics, percentage of predicted forced expiratory volume in 1 second $\left(\mathrm{FEV}_{1} \%\right.$ predicted $)$, age, and mMRC were associated $(p<0.10)$ with therapy adherence to ICSs (Table 1) on the one hand and with time to first severe AECOPD, time to first CAP (except for mMRC), and time to death on the other hand (data not shown), and were therefore included in these models as potential confounders. Furthermore, for the models on time to first severe AECOPD and CAP, myocardial infarction was also included, while for the time to death model, tiotropium use was included as an additional confounder.

$\mathrm{FEV}_{1} \%$ predicted and mMRC were associated $(p<0.10)$ with therapy adherence to tiotropium (Table 2 ) on the one 
Table 2 Baseline characteristics of patients using tiotropium

\begin{tabular}{|c|c|c|c|c|c|c|}
\hline \multirow[t]{2}{*}{ Characteristics } & \multirow{2}{*}{$\begin{array}{l}\text { Overall } \\
\text { Tiotropium } \\
(n=505)\end{array}$} & \multicolumn{4}{|c|}{ Adherence category: first 6 months of tiotropium use } & \multirow[t]{2}{*}{$p$-value } \\
\hline & & $\begin{array}{l}\text { Optimal use, } \\
\geq 75-\leq 125 \% \\
(n=360)\end{array}$ & $\begin{array}{l}\text { Suboptimal } \\
\text { use, } \geq 50-<75 \% \\
(n=64)\end{array}$ & $\begin{array}{l}\text { Underuse, } \\
<\mathbf{5 0 \%} \\
(\mathrm{n}=\mathbf{3 6})\end{array}$ & $\begin{array}{l}\text { Overuse, } \\
>125 \% \\
(n=45)\end{array}$ & \\
\hline Age (years), mean (SD) & $66.0(9.8)$ & $65.9(9.4)$ & $67.1(11.1)$ & $64.0($ (II.I) & $66.8(9.8)$ & 0.443 \\
\hline Sex (male), n (\%) & $310(61.4)$ & $222(61.7)$ & $38(59.4)$ & $21(58.3)$ & $29(64.4)$ & 0.932 \\
\hline \multicolumn{7}{|l|}{ Smoking status, n (\%) } \\
\hline Current smoker & $149(29.5)$ & $94(26.1)$ & $24(37.5)$ & $14(38.9)$ & $17(37.8)$ & 0.073 \\
\hline Ex-smoker & $356(70.5)$ & $266(73.9)$ & $40(62.5)$ & $22(6 I .1)$ & $28(62.2)$ & \\
\hline \multicolumn{7}{|l|}{ Lung function, mean (SD) } \\
\hline $\mathrm{FEV}_{1}(\mathrm{~L})$ & $1.4(0.56)$ & $1.4(0.56)$ & $1.4(0.53)$ & $1.7(0.66)$ & I.3 $(0.46)$ & 0.021 \\
\hline $\mathrm{FEV}, \%$ predicted & $51.7(17.7)$ & $51.9(17.7)$ & $51.1(16.0)$ & $57.1(21.1)$ & $47.1(16.3)$ & 0.090 \\
\hline $\mathrm{FEV}_{1} / \mathrm{NC}$ ratio & $43.5(12.8)$ & $43.4(12.5)$ & $43.2(13.2)$ & $47.9(16.3)$ & $51.7(17.7)$ & 0.097 \\
\hline mMRC, mean $(S D)^{a}$ & I.7| (I.2) & $1.59(1.8)$ & $1.93(1.17)$ & $2.00(1.37)$ & $2.15(1.41)$ & 0.007 \\
\hline ICS use, $n(\%)$ & $440(87.1)$ & $316(87.8)$ & $55(85.9)$ & $30(83.3)$ & $39(86.7)$ & 0.876 \\
\hline \multicolumn{7}{|l|}{ Comorbidities, n (\%) } \\
\hline Heart failure & $86(17.0)$ & $67(18.6)$ & $4(6.3)$ & $7(19.4)$ & $8(17.8)$ & 0.108 \\
\hline Myocardial infarction & $18(3.6)$ & $10(2.8)$ & $3(4.7)$ & I (2.8) & $4(8.9)$ & 0.161 \\
\hline Diabetes mellitus & $35(6.9)$ & $21(5.8)$ & $4(6.3)$ & $6(16.7)$ & $4(8.9)$ & 0.100 \\
\hline
\end{tabular}

Note: ${ }^{a} m M R C$ data available for optimal use $(n=334)$, suboptimal use $(n=59)$, underuse $(n=33)$, and overuse $(n=39)$.

Abbreviations: SD, standard deviation; $\mathrm{FEV}_{1}$, forced expiratory volume in I second; $\mathrm{FEV}, \%$ predicted, percentage of predicted forced expiratory volume in I second; VC, vital capacity; mMRC, modified Medical Research Council; ICS, inhaled corticosteroid.

hand and with time to first severe AECOPD, CAP, and time to death on the other hand (data not shown), and were therefore included as potential confounders in the tiotropium models.

\section{ICSs}

\section{Time to first severe AECOPD}

The median duration use (until event or end of follow-up) was 24 months (IQR 12-36 months). Analyses showed no increased risk of a hospital admission for severe AECOPD for nonadherent ICS use (unadjusted: suboptimal use HR 1.3 [95\% CI 0.9-1.8], underuse HR 1.0 [95\% CI 0.7-1.4], and overuse HR 1.4 [95\% CI 1.0-2.0] and adjusted: suboptimal use HR 1.2 [95\% CI 0.8-1.8], underuse HR 0.8 [95\% CI 0.51.2], and overuse HR 1.2 [95\% CI 0.8-1.7; Table 4]). A lower $\mathrm{FEV}_{1} \%$ predicted and a higher mMRC score at baseline

Table 3 ICSs that were investigated

\begin{tabular}{ll}
\hline Medication & $\begin{array}{l}\text { Months used, } \\
\text { median (IQR) }\end{array}$ \\
\hline Ciclesonide $(\mathrm{n}=22)$ & $23.5($ I5.8-35.5) \\
Fluticasone $(\mathrm{n}=73)$ & $25.7(I 2.5-34.9)$ \\
Formoterol/budesonide $(\mathrm{n}=9 \mathrm{I})$ & $31.2(15.9-36.5)$ \\
Salmeterol/fluticasone $(\mathrm{n}=493)$ & $27.4(\mid 3.2-34.7)$ \\
Budesonide $(\mathrm{n}=44)$ & $28.2(\mid 7.4-36.7)$ \\
Beclomethasone $(\mathrm{n}=44)$ & $15.7(7.5-3 \mid .7)$ \\
Formoterol/beclomethasone $(\mathrm{n}=8)$ & $9.3(4.0-16.5)$ \\
\hline
\end{tabular}

Abbreviations: ICS, inhaled corticosteroid; IQR, interquartile range. were associated with a higher risk of hospital admission for a severe AECOPD: HR 2.04 (95\% CI 1.43-2.50) and HR $1.4(95 \%$ CI $1.2-1.5)$, respectively.

\section{Time to first CAP}

The median duration use (until event or end of follow-up) was 30 months (IQR 18-36 months). There was no relationship between the different adherence categories and the risk of CAP (unadjusted: suboptimal use HR 1.1 [95\% CI 0.7-1.7], underuse HR 1.2 [95\% CI 0.8-1.8], and overuse HR 1.1 [95\% CI 0.7-1.7] and adjusted: suboptimal use HR 1.0 [95\% CI 0.6-1.6], underuse HR 1.1 [95\% CI 0.7-1.7], and overuse HR 0.9 [95\% CI 0.6-1.5; Table 4]). A higher $\mathrm{FEV}_{1} \%$ predicted at baseline was associated with a lower risk of CAP: HR 0.7 (95\% CI 0.5-0.97).

\section{Mortality}

The median duration use (until event or end of follow-up) was 36 months (IQR 24-36 months). Unadjusted analysis showed a significant increased mortality risk for patients with suboptimal use (HR 2.5 [95\% CI 1.5-4.2]) or underuse (HR 5.0 [95\% CI 3.2-7.6]), compared to those with optimal use. This risk increased to 2.9 (95\% CI 1.7-5.1) for suboptimal use and 5.3 (95\% CI 3.3-8.5) for underuse compared to optimal use after correction (Table 4). A higher mMRC score was also associated with a higher mortality risk, HR 1.2 (95\% CI 0.99-1.4). 
Table 4 Univariate and multivariate Cox regression analyses with time-varying coefficients of therapy adherence to ICSs

\begin{tabular}{|c|c|c|c|c|c|c|c|}
\hline & \multirow{2}{*}{$\begin{array}{l}\text { Adherence categoryl } \\
\text { confounder }\end{array}$} & \multicolumn{3}{|c|}{ Univariate } & \multicolumn{3}{|c|}{ Multivariate } \\
\hline & & HR & $95 \% \mathrm{Cl}$ & $p$-value & HR & $95 \% \mathrm{Cl}$ & $p$-value \\
\hline Hospital & Suboptimal use & 1.3 & $0.9-1.8$ & 0.135 & 1.2 & $0.8-1.8$ & 0.382 \\
\hline \multirow[t]{6}{*}{ admission } & Underuse & 1.0 & $0.7-1.4$ & & 0.8 & $0.5-1.2$ & \\
\hline & Overuse & 1.4 & $1.0-2.0$ & & 1.2 & $0.8-1.7$ & \\
\hline & $\mathrm{FEV}_{1} \%$ predicted & & & & 0.5 & $0.4-0.7$ & $<0.001$ \\
\hline & Age & & & & 1.0 & $1.0-1.0$ & 0.295 \\
\hline & $\mathrm{mMRC}$ & & & & 1.4 & $1.2-1.5$ & $<0.001$ \\
\hline & MI & & & & 1.9 & I.I-3.4 & 0.032 \\
\hline \multirow[t]{6}{*}{ Pneumonia } & Suboptimal use & 1.1 & $0.7-1.7$ & 0.918 & 1.0 & $0.6-1.6$ & 0.940 \\
\hline & Underuse & 1.2 & $0.8-1.8$ & & I.I & $0.7-1.7$ & \\
\hline & Overuse & 1.1 & $0.7-1.7$ & & 0.9 & $0.6-1.5$ & \\
\hline & $\mathrm{FEV}_{1} \%$ predicted & & & & 0.7 & $0.5-1.0$ & 0.007 \\
\hline & Age & & & & 1.0 & $1.0-1.0$ & 0.026 \\
\hline & MI & & & & 1.9 & I.I-3.5 & 0.047 \\
\hline \multirow[t]{7}{*}{ Mortality } & Suboptimal use & 2.5 & I.5-4.2 & $<0.001$ & 2.9 & $|.7-5|$. & $<0.001$ \\
\hline & Underuse & 5.0 & $3.2-7.6$ & & 5.3 & $3.3-8.5$ & \\
\hline & Overuse & 1.2 & $0.6-2.3$ & & 0.9 & $0.4-2.1$ & \\
\hline & $\mathrm{FEV}_{1} \%$ predicted & & & & 0.3 & $0.2-0.5$ & $<0.001$ \\
\hline & Age & & & & I.I & I.0-I.| & $<0.001$ \\
\hline & $\mathrm{mMRC}$ & & & & 1.2 & I.0-1.4 & 0.009 \\
\hline & Tiotropium use & & & & 1.2 & $0.8-1.8$ & 0.635 \\
\hline
\end{tabular}

Note: Optimal use set as reference category.

Abbreviations: ICS, inhaled corticosteroid; HR, hazard ratio; FEV,\% predicted, percentage of predicted forced expiratory volume in I second; mMRC, modified Medical Research Council; MI, myocardial infarction.

\section{Tiotropium}

\section{Time to first severe AECOPD}

The median duration use (until event or end of follow-up) was 24 months (IQR 12-36 months). Patients with suboptimal use, underuse, or overuse of tiotropium had a significantly increased risk of a hospital admission for severe AECOPD compared to those with optimal use with unadjusted HRs of 3.1 (95\% CI 2.2-4.5), 1.8 (95\% CI 1.2-2.9), and 2.4 (95\% CI
1.5-3.8), respectively. After correction, the risk of suboptimal use and underuse remained almost the same at respectively 3.0 (95\% CI 2.0-4.5) and 1.9 (95\% CI 1.2-3.1), while the risk of overuse decreased to 1.8 (95\% CI 1.1-3.2; Table 5). Next to this, a lower $\mathrm{FEV}_{1} \%$ predicted and a higher mMRC score at baseline were associated with a higher risk of hospital admission for a severe AECOPD with, respectively, an HR of 2.0 (95\% CI 1.4-2.5) and an HR of 1.4 (95\% CI 1.2-1.6).

Table 5 Univariate and multivariate Cox regression analyses with time-varying coefficients of therapy adherence to tiotropium

\begin{tabular}{|c|c|c|c|c|c|c|c|}
\hline & \multirow{2}{*}{$\begin{array}{l}\text { Adherence categoryl } \\
\text { confounder }\end{array}$} & \multicolumn{3}{|c|}{ Univariate } & \multicolumn{3}{|c|}{ Multivariate } \\
\hline & & HR & $95 \% \mathrm{Cl}$ & $p$-value & HR & $95 \% \mathrm{Cl}$ & $p$-value \\
\hline Hospital & Suboptimal use & 3.1 & $2.1-4.5$ & $<0.001$ & 3.0 & $2.0-4.5$ & $<0.001$ \\
\hline \multirow[t]{4}{*}{ admission } & Underuse & 1.8 & $1.2-2.9$ & & 1.9 & $1.2-3.1$ & \\
\hline & Overuse & 2.4 & $1.5-3.8$ & & 1.8 & $1.1-3.2$ & \\
\hline & $\mathrm{FEV}_{1} \%$ predicted & & & & 0.5 & $0.4-0.7$ & $<0.001$ \\
\hline & $\mathrm{mMRC}$ & & & & 1.4 & $1.2-1.6$ & $<0.001$ \\
\hline \multirow[t]{5}{*}{ Pneumonia } & Suboptimal use & 2.3 & $1.3-3.9$ & 0.014 & 2.2 & $1.2-4.0$ & 0.018 \\
\hline & Underuse & 1.5 & $0.8-2.8$ & & 1.7 & $0.9-3.2$ & \\
\hline & Overuse & 2.2 & I.I-4.4 & & 2.3 & I.2-4.7 & \\
\hline & $\mathrm{FEV}_{1} \%$ predicted & & & & 0.6 & $0.3-0.9$ & 0.001 \\
\hline & $\mathrm{mMRC}$ & & & & 1.2 & $1.0-1.4$ & 0.057 \\
\hline \multirow[t]{5}{*}{ Mortality } & Suboptimal use & 4.1 & $2.4-7.3$ & $<0.001$ & 3.9 & $2.1-7.5$ & $<0.001$ \\
\hline & Underuse & 5.6 & $3.4-9.1$ & & 6.4 & $3.8-10.8$ & \\
\hline & Overuse & 1.7 & $0.7-4.4$ & & I.I & $0.3-3.7$ & \\
\hline & $\mathrm{FEV}_{1} \%$ predicted & & & & 0.3 & $0.2-0.5$ & $<0.001$ \\
\hline & $\mathrm{mMRC}$ & & & & 1.2 & $1.0-1.5$ & 0.060 \\
\hline
\end{tabular}

Note: Optimal use set as reference category.

Abbreviations: HR, hazard ratio; FEV,\% predicted, percentage of predicted forced expiratory volume in I second; mMRC, modified Medical Research Council. 


\section{Time to first CAP}

The median duration use (until event or end of follow-up) was 30 months (IQR 12-36 months). Patients showing suboptimal use or overuse of tiotropium had an unadjusted increased risk for CAP compared to those showing optimal use with an HR of 2.3 (95\% CI 1.3-3.9) and an HR of 2.2 (95\% CI 1.1-4.4), respectively. The twofold increased risk of CAP for suboptimal use and overuse remained after correction with an HR of 2.2 (95\% CI 1.2-4.0) and an HR of 2.3 (95\% CI 1.2-4.7), respectively (Table 5). A higher FEV ${ }_{1} \%$ predicted at baseline was also associated with a lower risk of CAP, HR 0.6 (95\% CI 0.4-0.9).

\section{Mortality}

The median duration use (until event or end of follow-up) was 36 months (IQR 24-36 months). Both suboptimal use and underuse of tiotropium were associated with a significant increased risk of mortality (Table 5). Unadjusted analysis showed a 4.1-fold (95\% CI 2.4-7.3) increased risk of dying in suboptimal users and a 5.6-fold (95\% CI 3.4-9.1) increased risk for underusers compared to optimal users (Table 5).

After correction, suboptimal use showed a 3.9-fold (95\% CI 2.1-7.5) and underuse a 6.4-fold (95\% CI 3.8-10.8) increased mortality risk (Table 5). Furthermore, a lower $\mathrm{FEV}_{1} \%$ predicted and a higher mMRC score at baseline were associated with a higher mortality risk with an HR of 3.3 (95\% CI 2.0-5.0) and an HR of 1.2 (95\% CI 0.99-1.5), respectively.

\section{Discussion}

Suboptimal use and underuse of ICSs and tiotropium were associated with a substantially increased mortality risk compared to optimal use. Suboptimal use and overuse of tiotropium were also associated with an increased risk of CAP. Next to this, nonadherence to tiotropium was associated with an increased risk of hospital admission for a severe AECOPD. An independent association between adherence to ICSs and hospital admission for a severe AECOPD or CAP could not be demonstrated.

A lower $\mathrm{FEV}_{1} \%$ predicted at baseline was associated with a higher risk of hospital admission for a severe AECOPD, $\mathrm{CAP}$, and mortality, while a higher mMRC score was associated with a higher risk of severe AECOPD and a higher risk of mortality in both ICSs and tiotropium users.

The current results on decreased mortality risk in patients who were adherent to ICSs are in line with the results of TORCH study that showed a borderline significant reduced risk on mortality with the use of fluticasone propionate combined with salmeterol. ${ }^{2}$ This risk seems even more increased in underusers $(<50 \%)$, who show an almost twofold increased mortality risk than suboptimal users (50\%-75\%), which implies the need to make also a distinction in the type of nonadherence. Our study results were not in line with Ismaila et $\mathrm{al}^{11}$ who showed that reduced adherence to fluticasone/salmeterol was associated with increased risks for moderate and severe COPD exacerbations. Overall optimal adherence in the COMIC cohort study was much higher (58\% vs 35\%), and Ismaila et al could not correct for lung function and $\mathrm{mMRC}$, which can possibly explain the observed differences.

The increased risk for CAP in ICS users as shown in, for example, the TORCH study (HR 1.5 for patients with adherence $>80 \%$ compared to those with nonuse of ICSs) could not be confirmed. ${ }^{4,6}$ A possible explanation could be that the COMIC study lacks statistical power due to the low number of CAP cases. Furthermore, the TORCH study investigated a specific dosage, namely, $500 \mu \mathrm{g}$ fluticasone twice daily, whereas in the COMIC study, lower dosages were used. This is supported by the findings of Ernst et $\mathrm{al}^{25}$ who suggested that there was a dose-related increase for pneumonia. Furthermore, the diagnosis of pneumonia was confirmed by X-ray in the COMIC cohort, which was not the case in the TORCH study. This could have led to misclassification of CAP in the TORCH study.

Both suboptimal use and underuse of tiotropium were associated with a significant increased mortality risk compared to optimal use. Furthermore, nonadherence to tiotropium compared to optimal use was associated with an increased morbidity risk. These effects could possibly be caused by the fact that the patient misses the protective effect of tiotropium as studied in the UPLIFT study and shown by Ismaila et al. ${ }^{3,11}$

The risk even seems to increase as adherence rates decrease, with higher risks in underusers than suboptimal users. A reason for taking less tiotropium could be that the patient is feeling well and does not see the need for using tiotropium. This is supported by the results that underuse is associated with a better lung function at baseline.

Whether the association between overuse of tiotropium and increased risk of severe AECOPD and CAP was caused by the medication or the underlying disease, although we corrected for lung function and $\mathrm{mMRC}$, cannot be ruled out due to the observational nature of the data. Since overuse is associated with a lower lung function and a higher $\mathrm{mMRC}$, it seems that overuse is related to COPD severity, which could explain the increased risk. Overuse could be due to an overall 
poor health condition, which results in feeling the need to use more medication. Another reason why patients can become overusers is an incorrect inhalation technique, since this can diminish the effect of the inhaled medication. Overuse can therefore be seen as a compensatory mechanism for not experiencing any relief of the medication used. Unfortunately, there are no data available on the inhalation technique in the cohort. In addition, lack of knowledge could be a reason for overuse. When a patient does not know what to expect from, for example, an ICS and experiences no immediate benefit, he or she could inhale again because the symptoms are not yet relieved. In addition, as shown previously, adherence to inhaled medication is related to the device in which the medication is delivered. ${ }^{26}$ For example, if a device does not provide inhalation feedback and a patient is not confident about having taken a dose, he or she can decide to inhale again to be sure. ${ }^{26}$

Nonadherence can also be a general behavior influenced by a patient's beliefs on his or her illness in relation to treatment recommendations. In COPD, disease and medication perception have not been described in much detail, and future research with, for example, in-depth interviews could provide more insight.

An advantage of the data of the COMIC cohort is the chance to assess the effect of ICSs and tiotropium in reallife COPD outpatients and not in a selected trial population. In addition, in the cohort, a valid diagnosis of COPD, lung function data, comorbidity data, and an X-ray confirmed that pneumonia is present. The possibility to correct for lung function, comorbidities, and $\mathrm{mMRC}$ in the analyses is another asset of this study. Finally, the follow-up of 3 years and determining the adherence over 6-month periods thus following adherence development over time are strong points as well.

A limitation of pharmacy data is that they only give an indication of drug refill patterns but not of the actual inhalation. The data show the maximum levels of drug use among the patients, and it is likely that the inhaled drug volumes are lower than the volumes dispensed by the pharmacy. Patients can collect the medication to appear adherent and dump the medication or store it in different places for convenience without actually using the medication. ${ }^{27-29}$ An electronic counting device with the flow meter could help to analyze and tackle this problem. However, these devices were not yet available at the start of this cohort.

Another possible limitation is the fact that this is a single-center study that may affect external validity since the adherence in this center seems somewhat better compared to other regions in the Netherland. ${ }^{12}$
Previously published main determinants of nonadherence in this cohort were lung function and having more anxiety for dyspnea (measured with the Clinical COPD Questionnaire question 3). ${ }^{14}$ An interesting additional outcome measure for future research would be to study the change in morbidity of patients based on longitudinal symptoms and quality of life assessments.

The described results raise questions about what should be done next. Patients who do not use their medication as prescribed might need extra attention because diverting from optimal adherence is significantly associated with morbidity and mortality. The community pharmacy can play an important role in recognizing these patients because adherence to medication starts with filling a prescription. In case of nonadherence, there should be a reflection on adherence and a starting point for further support and guidance toward optimal use of medication.

\section{Conclusion}

Poor adherence to ICSs and tiotropium was significantly associated with a substantial higher mortality risk. Nonadherence to tiotropium was also associated with an increased risk of severe AECOPD and CAP. In contrast to this, an independent association between adherence to ICSs and severe AECOPD or CAP could not be demonstrated. Future research is warranted to confirm these associations and to study whether improving adherence reduces mortality and morbidity.

\section{Acknowledgment}

This study was partly supported by an unrestricted research grant of GlaxoSmithKline.

\section{Disclosure}

The authors report no conflicts of interest in this work.

\section{References}

1. Global Initiative for Chronic Obstructive Lung Disease (GOLD). From the Global Strategy for the Diagnosis, Management and Prevention of COPD. 2011. Available from: http://www.goldcopd.org/. Accessed December 11, 2012. Ref Type: Internet Communication.

2. Vestbo J, Anderson JA, Calverley PM, et al. Adherence to inhaled therapy, mortality and hospital admission in COPD. Thorax. 2009; 64(11):939-943.

3. Celli B, Decramer M, Kesten S, et al; UPLIFT Study Investigators Mortality in the 4-year trial of tiotropium (UPLIFT) in patients with chronic obstructive pulmonary disease. Am J Respir Crit Care Med. 2009; 180(10):948-955.

4. Calverley PM, Anderson JA, Celli B, et al; TORCH Investigators. Salmeterol and fluticasone propionate and survival in chronic obstructive pulmonary disease. $N$ Engl J Med. 2007;356(8):775-789.

5. Morjaria JB, Rigby A, Morice AH. Inhaled corticosteroid use and the risk of pneumonia and COPD exacerbations in the UPLIFT study. Lung. 2017;195(3):281-288. 
6. Crim C, Calverley PM, Anderson JA, et al. Pneumonia risk in COPD patients receiving inhaled corticosteroids alone or in combination: TORCH study results. Eur Respir J. 2009;34(3):641-647.

7. Finney L, Berry M, Singanayagam A, Elkin SL, Johnston SL, Mallia P. Inhaled corticosteroids and pneumonia in chronic obstructive pulmonary disease. Lancet Respir Med. 2014;2(11):919-932.

8. Bourbeau J, Aaron SD, Barnes NC, Davis KJ, Lacasse Y, Nadeau G. Evaluating the risk of pneumonia with inhaled corticosteroids in COPD: Retrospective database studies have their limitations SA. Respir Med. 2017;123:94-97.

9. Wilkie M, Finch S, Schembri S. Inhaled corticosteroids for chronic obstructive pulmonary disease-the shifting treatment paradigm. COPD. 2015;12(5):582-590.

10. Magnussen H, Disse B, Rodriguez-Roisin R, et al; WISDOM Investigators. Withdrawal of inhaled glucocorticoids and exacerbations of COPD. N Engl J Med. 2014;371(14):1285-1294.

11. Ismaila A, Corriveau D, Vaillancourt J, et al. Impact of adherence to treatment with tiotropium and fluticasone propionate/salmeterol in chronic obstructive pulmonary diseases patients. Curr Med Res Opin. 2014;30(7):1427-1436.

12. Koehorst-ter Huurne K, Movig K, van der Valk P, van der Palen J, Brusse-Keizer M. Differences in adherence to common inhaled medications in COPD. COPD. 2015;12(6):643-648.

13. Brusse-Keizer M, Zuur-Telgen M, van der Palen J, et al. Adrenomedullin optimises mortality prediction in COPD patients. Respir Med. 2015;109(6):734-742.

14. Koehorst-ter Huurne K, Kort S, van der Palen J, et al. Quality of life and adherence to inhaled corticosteroids and tiotropium in COPD are related. Int J Chron Obstruct Pulmon Dis. 2016;11:1679-1688.

15. Quanjer PH, Tammeling GJ, Cotes JE, Pedersen OF, Peslin R, Yernault JC. Lung volumes and forced ventilatory flows. Report working party standardization of lung function tests, European Community for Steel and Coal. Official statement of the European Respiratory Society. Eur Respir J Suppl. 1993;16:5-40.

16. Mahler DA, Wells CK. Evaluation of clinical methods for rating dyspnea. Chest. 1988;93(3):580-586.

17. Cecere LM, Slatore CG, Uman JE, et al. Adherence to long-acting inhaled therapies among patients with chronic obstructive pulmonary disease (COPD). COPD. 2012;9(3):251-258.
18. Krigsman K, Moen J, Nilsson JL, Ring L. Refill adherence by the elderly for asthma/chronic obstructive pulmonary disease drugs dispensed over a 10-year period. J Clin Pharm Ther. 2007;32(6):603-611.

19. van Grunsven PM, van Schayck CP, van Deuveren M, van Herwaarden CL, Akkermans RP, van Weel C. Compliance during long-term treatment with fluticasone propionate in subjects with early signs of asthma or chronic obstructive pulmonary disease (COPD): results of the detection, intervention, and monitoring program of COPD and asthma (DIMCA) study. J Asthma. 2000;37(3):225-234.

20. Sikka R, Xia F, Aubert RE. Estimating medication persistency using administrative claims data. Am J Manag Care. 2005;11(7):449-457.

21. Lim WS, van der Eerden MM, Laing R, et al. Defining community acquired pneumonia severity on presentation to hospital: an international derivation and validation study. Thorax. 2003;58(5):377-382.

22. Stricker BH, Stijnen T. Analysis of individual drug use as a time-varying determinant of exposure in prospective population-based cohort studies. Eur J Epidemiol. 2010;25(4):245-251.

23. Thomas L, Reyes EM. Tutorial: survival estimation for cox regression models with time-varying coefficients using SAS and R. J Stat Softw. 2014;61(1).

24. R Core Team. R: A Language and Environment for Statistical Computing. Vienna, Austria: R Foundation for Statistical Computing; 2017. Available from: https://www.R-project.org/. Accessed December 11, 2017. Ref Type: Internet Communication.

25. Ernst P, Gonzalez AV, Brassard P, Suissa S. Inhaled corticosteroid use in chronic obstructive pulmonary disease and the risk of hospitalization for pneumonia. Am J Respir Crit Care Med. 2007;176(2):162-166.

26. Koehorst-ter Huurne K, Movig K, van der Valk P, van der Palen J, Brusse-Keizer $\mathrm{M}$. The influence of type of inhalation device on adherence of COPD patients to inhaled medication. Expert Opin Drug Deliv. 2015;13(4):469-475.

27. Simmons MS, Nides MA, Rand CS, Wise RA, Tashkin DP. Unpredictability of deception in compliance with physician-prescribed bronchodilator inhaler use in a clinical trial. Chest. 2000;118(2):290-295.

28. Haupt D, Krigsman K, Nilsson JL. Medication persistence among patients with asthma/COPD drugs. Pharm World Sci. 2008;30(5):509-514.

29. Choo PW, Rand CS, Inui TS, et al. Validation of patient reports, automated pharmacy records, and pill counts with electronic monitoring of adherence to antihypertensive therapy. Med Care. 1999;37(9):846-857.
International Journal of COPD

\section{Publish your work in this journal}

The International Journal of COPD is an international, peer-reviewed journal of therapeutics and pharmacology focusing on concise rapid reporting of clinical studies and reviews in COPD. Special focus is given to the pathophysiological processes underlying the disease, intervention programs, patient focused education, and self management protocols.

\section{Dovepress}

This journal is indexed on PubMed Central, MedLine and CAS. The manuscript management system is completely online and includes a very quick and fair peer-review system, which is all easy to use. Visit http://www.dovepress.com/testimonials.php to read real quotes from published authors. 